\title{
Indigena, cyberbulliyng e a estereotipação do sujeito no mercado de trabalho
}

\author{
Indigenous, cyberbulliyng and stereotypes in labor market
}

\author{
Fabiana Ferrari Nunes ${ }^{1}$ \\ Universidade Federal de Mato Grosso do Sul
}

\begin{abstract}
- RESUMO: O discurso constitui um cenário em que estão envolvidos a língua, o sujeito e o espaço histórico social e cultural. A partir dessa premissa o indígena tem saído das aldeias para os centros urbanos em busca de capacitação profissional. Essa visibilidade no mercado de trabalho na sociedade hegemônica, tem levado o indígena graduado, profissionalizado ao enfrentamento de discursos cristalizados que os representam como incapazes. Discursos que retratam a distinção entre índios e brancos emergem na sociedade hegemônica e reverberam nas mídias sociais por meio de ciberpráticas que se chocam com o acontecimento discursivo: o índio e suas novas práticas identitárias. Entendido esse conceito, este trabalho tem por objetivos estudar representações elaboradas por/sobre indígenas, no mercado de trabalho, em ambientes virtuais. Por meio do método arqueogenealógico, proposto por Foucault (1990; 1997; 1999; 2007), analisam-se recortes de publicações on-line de e sobre trabalhadores indígenas postadas na rede social Facebook. Para tanto, utiliza-se o arcabouço teórico da Análise do Discurso de origem francesa (AD), a partir dos estudos de Coracini (2007), Pêcheux (1988; 1990), Orlandi (1999) e Authier-Révuz (1990; 1998), numa visada transdisciplinar de pesquisa que considera a produtiva relação com a psicanálise (LACAN, 1973) e Freud (1929). Almeja-se verificar se os discursos postados por índios e brancos acerca do índio no mercado de trabalho estão inscritos em um novo acontecimento discursivo: o cyberbullying, considerada a prática da crueldade on line, que pode agredir o sujeito silenciosamente e muitas vezes anonimamente, dificultando a identificação do agressor.
\end{abstract}

- PALAVRAS-CHAVE: Indígenas. Mídia. Cyberbullying.

- ABSTRACT: The discourse constitutes a scenario in which the language, the subject and the social and cultural historical space are involved. From this premise the indigenous has left the villages to the urban centers in search of professional qualification. This visibility in the labor market in hegemonic society has led the indigenous graduate, professionalized to face crystallized discourses that represent them as incapable. Discourses that portray the distinction between Indians and whites emerge in hegemonic society and reverberate in social media through cyberpractices that clash with the discursive event: the Indian and his new identity practices. Understood this concept, this work aims to study representations elaborated by / on indigenous, in the labor market, in virtual environments. Through the archaeogeneal method, proposed by Foucault (1990; 1997; 1999; 2007), we analyze clippings of online publications of and about indigenous workers posted on the social network Facebook. For this, the theoretical framework of Discourse Analysis of French origin (AD) is used, based on the studies of Coracini (2007), Pêcheux (1988, 1990), Orlandi (1999) and Authier-Révuz 1990, 1998), in a transdisciplinary research perspective that considers the productive relationship with psychoanalysis (LACAN, 1973) and Freud (1929). It is hoped to verify if the speeches posted by Indians and whites about the Indian in the labor market are inscribed in a new discursive event: cyberbullying, considered the practice of cruelty on line, that can attack the subject silently and often anonymously, making it difficult The identification of the aggressor.

- KEYWORDS: Indian. Media. Cyberbullying.

\footnotetext{
${ }^{1}$ Mestranda do Programa de Pós-Graduação em Letras da UFMS/Três Lagoas. psicoferrari@hotmail.com
} 


\section{Introdução}

A história indígena no Brasil foi marcada pela imposição de uma unidade nacional que excluía a diversidade na qual índios deveriam deixar de serem índios.

$\mathrm{Na}$ época do colonialismo, eram impostas regras pelo branco aos indígenas, visando instaurar sua ideologia. O processo de catequização pelos jesuítas perpassa pela sujeição, dominação e extermínio chegando à contemporaneidade. Esse imaginário que submete os indígenas a um grupo inferiorizado, distante da ciência, da "cultura", predomina até os dias de hoje, o que faz com que os indígenas arrisquem-se e, ao transitarem pelo universo branco, sofram preconceitos das mais variadas formas, porém algumas empresas têm proporcionado ao indígena a oportunidade de desenvolver atividades trabalhistas. Questiona se essas práticas se são de fato inclusivas, ou se mascaram o histórico percurso de exclusão a que esse sujeito tem sido submetido. Neste artigo, buscamos, por meio da análise da materialidade linguística, nas marcas linguísticas de heterogeneidade apontadas por Authier-Révuz (1998) e no silenciamento de que fala Orlandi (2007), identificar a forma como a identidade do indígena é discursivizada e, pelo método arqueogenealógico de Foucault (2007), analisar discursos e problematizar essa discursivização no domínio discursivo da internet, remetendo ao que se tem chamado de ciberbullying. Para tanto, analisamos um recorte de uma reportagem jornalística postada na rede social Facebook $^{2}$, na página de um jornal paranaense, a Gazeta do Povo.

Buscamos compreender a complexidade das questões contidas no discurso e o sentido das palavras que, submetidas às condições ideológicas das relações de produção (sejam elas em sua formação, produção, transformação ou reprodução), vêm esclarecer pontos que dizem respeito à subjetividade, à memória discursiva e ao pensamento logocêntrico que regulam o que o sujeito pode e deve dizer, bem como o que não pode ou não deve ser dito (CORACINI, 2007). Assim, a transdisciplinaridade se faz necessária, uma vez que tal aporte teórico considera a linguagem em sua incompletude.

\section{Um breve percurso histórico}

Em 1910, encontram-se as raízes institucionais dos direitos indígenas, com a formação de um órgão indigenista específico, o Serviço de Proteção ao Índio - SPI -, destinado a mediar a relação entre o capital e os povos indígenas, mediante a "pacificação" dos índios e o reconhecimento do direito deles à posse da terra e a viver de acordo com os próprios costumes. Em 1960, o SPI é extinto, dando lugar à Funai Fundação Nacional do Índio -, encarregada de acelerar a integração do indígena à economia do mercado, de assegurar o respeito ao índio, garantir a posse das terras e viabilizar pesquisas científicas, entre outras obrigações (PROENÇA, 2017).

A despeito das conquistas, esse período também não foi pacífico. Em 1988, promulga-se a "Constituição Cidadã", para cuja redação houve uma grande mobilização dos índios, que desempenharam um papel fundamental de pressão no acordo final votado e aprovado pelo plenário, em cujo art. 231 consta: "São reconhecidos aos índios sua organização social, costumes, línguas, crenças e tradições, e os direitos originários sobre a terra que tradicionalmente ocupam, competindo à União demarcá-las, proteger e fazer respeitar todos os seus bens". Em 1996, viria a LDB 9394/96, incluindo a

\footnotetext{
${ }^{2}$ O Facebook é uma rede social gratuita, em que os usuários criam perfis que contêm fotos e listas de interesses pessoais. Esses usuários trocam mensagens privadas ou públicas entre si e entre os participantes de grupos de amigos. A rede conta com várias ferramentas, como murais, aplicativos de eventos (onde se podem convidar e selecionar amigos para um determinado evento), entre outros.
} 
Educação Indígena no rol das preocupações institucionais e oficiais brasileiras, entre outras prerrogativas legais (PROENÇA, 2017).

Segundo Uyeno (2014), na nova ordem da modernidade, a formação de cidadãos implica o desenvolvimento de suas habilidades e potenciais como trabalhador. Nesse "novo" território, o índio desloca-se para a região urbana em busca de oportunidades oferecidas no mercado de trabalho branco. Conforme afirma Orlandi (2002 p. 91), “[...]os índios não estão mais só nas aldeias distantes. Estão na cidade”. A isso acrescentamos: e estão participando do mundo do trabalho.

\section{Fundamentação teórica}

Pêcheux (1988) mostra que a língua tem a sua materialidade discursiva, ou seja, a tomada de um enunciado pressupõe a consideração das condições de produção. Para a teoria discursiva pecheuxtiana a base da língua, conjunto de estruturas fonológicas, morfológicas e sintáticas, possui uma autonomia relativa. E o discurso não é, simplesmente, um objeto dado no mundo, como se fosse algo transparente. Assim, acreditamos, com Orlandi (1999), que o discurso, em sua condição de objeto linguístico, histórico e social, é o ponto de articulação da materialidade discursiva que o compõe (verbo-visual) e das condições sócio-históricas de seu aparecimento (a exterioridade). Efeito de linguagem, o discurso é espaço de produção de saber, de funcionamento de poder, de representações e imagens e, pois, de fabricação de verdades. (FOUCAULT, 1997).

É no interior do discurso que uma parte da história do tempo presente vem sendo contada, como ocorre nas redes sociais. E, nesses espaços "democráticos", irrompem acontecimentos que inscrevem a subjetividade em trajetos de representação, (des)identificação, positivização/negativização de identidades, (in)visibilidades e silenciamentos. (ORLANDI, 2007).

Orlandi (2007) fala de um silêncio fundador, presente em toda linguagem e em todas as palavras, e da "política do silêncio", que se subdivide em silêncio constitutivo (todo dizer silencia algo) e silenciamento, que corresponde a submeter alguém a opressão, calar para estabelecer determinados sentidos em detrimento de outros; trata-se de um não dizer para ocultação de sentidos. Para analisar uma discursividade "local" (que envolve o dito e o não dito), um método produtivo é o arqueogenealógico (FOUCAULT, 2007), por meio do qual se podem escavar regras que permeiam as formações discursivas de determinado discurso, constitutivas do arquivo (arqueologia) e, ao mesmo tempo, ativar as conflituosas relações de poder exercidas no discurso (genealogia) e os saberes que emergem dessa discursividade.

Neste trabalho, consideramos o arquivo das dizibilidades sobre o índio ingressante no mundo do trabalho que circulam no Facebook, priorizando a produtividade da língua, em sua dimensão material, em sua possibilidade de falha, bem como na sua dispersão de espaço de lutas e de conflitos.

\section{Das condições de produção à análise}

Para o gesto analítico a seguir, faz-se necessário informar que o recorte (R1) foi retirado de uma reportagem postada na página do jornal Gazeta do Povo no Facebook ${ }^{3}$.

\footnotetext{
${ }^{3}$ O Facebook é uma rede social gratuita, em que os usuários criam perfis que contêm fotos e listas de interesses pessoais. Esses usuários trocam mensagens privadas ou públicas entre si e entre os participantes de grupos de amigos. A rede conta com várias ferramentas, como murais, aplicativos de eventos (onde se podem convidar e selecionar amigos para um determinado evento), entre outras.
} 
O jornal Gazeta do Povo, lançado em 1919, é um provedor de informação, sendo considerado o maior grupo de comunicação do Paraná (GRPCOM - Grupo Paranaense de Comunicação), segundo informações contidas no site. A reportagem, sob o título Índios combatem preconceito, integra a seção "Inclusão" do jornal e contém entrevista ao cacique Valdir José Kokoj dos Santos. Subdividida em quatros subitens, traz aspectos ligados à cultura dos povos de etnia Caingangue, ao ensino como ferramenta de inserção para o mercado de trabalho, questões ligadas aos desafios da geração de empregos para os índios e a dupla exclusão sofrida por esses povos.

R1 foi selecionado da parte introdutória da reportagem, em que parece prevalecer o discurso do jornal, mediado pela voz do sujeito-enunciador jornalista:

\begin{abstract}
R1: [...] Ao mesmo tempo em que tentam manter suas tradições históricas, muitos caingangues buscam a inserção na sociedade. Para esse objetivo, o ingresso ao mercado de trabalho é peça fundamental e 80 deles participam de uma iniciativa apontada como modelo. Diariamente, o grupo sai da área onde vive e vai de ônibus até a cidade vizinha de Pato Branco trabalhar na Atlas Eletrodomésticos, a terceira maior fabricante de fogões a gás do país. Devido à escassez de trabalhadores, a empresa procurou em 2008 por mão de obra indígena. Superado o receio inicial, 20 índios foram chamados e logo viram os resultados, com alta integração, regularidade e gosto pelo que fazem. (Post Gazeta do Povo. Índios combatem o preconceito, 2011. Grifos nossos).
\end{abstract}

Por estes dizeres é possível observar que o enunciador se encontra na posição sujeito do branco ao descrever que é o sujeito outro - o índio caingangue - que se desloca da área onde vive e vai de ônibus até a cidade vizinha de Pato Branco trabalhar [...] em busca de inserção na sociedade. Pela análise do dito, interpreta-se, nos dois primeiros períodos do recorte, que esse enunciador representa o índio caingangue como alguém que está fora da sociedade, na qual busca incluir-se pela entrada no mercado de trabalho. Também se interpreta que a iniciativa não é do índio, mas da empresa referida e, por extensão, do branco: uma oportunidade que este "generosamente" oferece ao indígena para incluí-lo.

Articulando esse dizer do redator da reportagem ao que este enuncia na sequência, é possível explicar o receio inicial da empresa: Superado o receio inicial, 20 índios foram chamados e logo viram os resultados, com alta integração, regularidade e gosto pelo que fazem. $O$ receio da empresa, aqui caracterizada como a terceira maior fabricante de fogões a gás do país, em contratar indígenas resulta dos discursos que compõem a memória discursiva, constituída por verdades moldadas e formatadas no bojo de uma sociedade hegemônica, demonstrando que só o branco tem capacidades para o mercado de trabalho, pois o branco é trabalhador.

Curioso é que a oração reduzida que inicia o período parece pretender camuflar o sujeito: pelo modo como o texto é a construído, cria-se uma ambiguidade acerca do de quem seria o "dono" do receio inicial: embora saibamos ter sido a empresa, não há referência explícita a ela; tenta-se deixar que o outro pense tratar-se do índio. Esse efeito persiste com o uso do plural em viram, que, gramaticalmente, pode referir-se aos 20 índios, porém, no plano do sentido, parece mais uma anáfora indireta (remissão a empresários/empresa). De acordo com Authier-Revuz (1998), as voltas enunciativas proporcionam ao enunciador os dúbios significados provocando o silenciamento no não dito. Essa produção de sentidos é provocada pela exterioridade em conjunto com os aspectos sociais e culturais. Orlandi (1988), por sua vez, considera que o significado emerge não apenas no que está dito, mas também no que está implícito. Segundo Riffel 
e Rodrigues (2014), na nova ordem da modernidade, a formação de cidadãos implica o desenvolvimento de suas habilidades e potenciais como trabalhador.

$\mathrm{Na}$ pretensa tentativa de conferir visibilidade ao sujeito índio, como aquele capaz de se profissionalizar, o efeito produzido no excerto é o avesso: o índio é estereotipado como alguém que inspira desconfiança e receio, pois não é visto como trabalhador. Importa acrescentar também que, para o sujeito-enunciador, o ingresso [de indígenas] ao mercado de trabalho é peça fundamental (remetendo aos discursos da produção de bens) e $\mathbf{8 0}$ deles [índios caingangues] participam de uma iniciativa apontada como modelo. Atravessados esses discursos pelas novas tecnologias na pósmodernidade e pela globalização, representam um índio "não trabalhador", que causaria problemas para a corporação. Ao aceitar incluir aqueles sujeitos considerados inferiores e excluídos da sociedade hegemônica e do meio capitalista, a empresa surpreende-se com os resultados alcançados - alta integração, regularidade e gosto pelo que fazem -, desconstruindo o estereótipo de que os índios não gostam de trabalhar. Como afirma Guerra (2010, p. 40) sobre "[...] a dificuldade que os brancos têm de reconhecer que os povos indígenas tem uma história, uma subjetividade, tal qual o 'civilizado', leva-os a pensar que a alma indígena é inferior e imanente à sua condição de bestialidade”. Compreendemos, com a autora, que tal preconceito contra o indígena é fruto de uma "visão etnocêntrica estereotipada" (GUERRA, 2010, p. 40).

A necessidade de imposição de um modelo a ser seguido, ou já estabelecido para a integração do sujeito índio contratado, marca a necessidade da normalização do trabalho, visando a homogeneizar as atividades exigidas para a execução de mão de obra indígena na empresa. Tal normalização consiste em colocar uma identidade para o índio como referência, e as outras como diferença. Para Guerra (2010), a normalização é um dos processos mais sutis pelos quais o poder se manifesta no campo da identidade.

Diante da constituição do outro trabalhador, o indígena passa a assumir um conflito interno entre ser índio e ser branco. Para Souza e Marques (2009), desde os primórdios da colonização, a população indígena é explorada e obrigada a se adaptar à convivência com o branco e a sua cultura, num processo contínuo e permanente de "embranquecimento". Distancia-se, assim, o indígena de suas raízes, de sua língua, costumes, tradições e ideologias, como percebido no trecho:

Ao considerar os povos indígenas como incapazes, não trabalhadores, o "sistema colonial europeu, perverso e dominador", ainda existente nos discursos da sociedade hegemônica, aqui representada pela empresa Atlas Eletrodomésticos, acaba por negar aos índios a agência sobre sua própria história, pois reverbera o pensamento iluminista de "bom selvagem". Esse efeito de sentido emerge da referência à necessidade de enquadrá-los em um modelo, de que obedeçam a uma regularidade na condução dos trabalhos.

Ao dizer que ao mesmo tempo em que tentam manter suas tradições históricas, muitos caingangues buscam a inserção na sociedade, o sujeito-enunciador deixa escapar, além da condição de excluído, o processo de hibridização do sujeito indígena inserido no mercado de trabalho, ressaltando a resistência dos caingangues junto ao poder normalizador. Para Foucault (1997, p. 241), "a partir do momento que há uma relação de poder, há uma possibilidade de resistência. Jamais somos aprisionados pelo poder: podemos sempre modificar sua dominação em condições determinantes e segundo uma estratégia precisa". Dessa forma, observa-se que, diante do sentimento de invisibilidade na sociedade hegemônica, advém ao sujeito indígena o desejo de ser completo por meio do sentimento de inserção na sociedade do branco. Assim, o índio permite-se ser assujeitado ao branco para alcançar uma ressignificação de sua representação como indígena, deixando de ser caracterizado como incapaz ou como 
aquele que não gosta de trabalhar, para ocupar a posição de sujeito operário. Ainda que inconsciente, todo esse processo de representação pode concorrer, no ambiente coorporativo, para o bullying - em geral chamado de assédio moral -, que costuma aparecer de maneira silenciosa por parte do agressor.

De acordo com Freitas et al. (2008), o assédio moral pode trazer diversas consequências para o agressor, para a vítima e para empresa. Assim, o sujeito agredido sofre agressões emocionais, que podem culminar em patologias, imediatas ou não. $\mathrm{Na}$ internet, que favorece a acessibilidade em qualquer tempo e em qualquer lugar, em meio aos muitos benefícios de aproximação e estreitamento de laços entre os sujeitos, essa prática também tem seu lugar, materializada em agressões verbais, exposição de imagens, veiculação de informações distorcidas, invasão de privacidade, veiculação de verdades cristalizadas. Encontro heterogêneo de diferentes posições histórico-culturais que mostra a capacidade da mente humana de não usar as informações de forma tão ética.

A essas posturas negativas na mídia, chama-se cyberbullying, que é a prática de agressões em meios digitais, podendo agredir o sujeito silenciosamente.

\section{Considerações Finais}

Mediante articulação de reflexões acerca da constituição identitária do sujeito indígena que atua no mercado de trabalho brasileiro, foi possível identificar silenciamentos significativos e marcas de estereotipação e de exclusão. Entendemos que o conhecimento, via discurso e seus efeitos de sentido, de representações que o outro elabora sobre o trabalhador indígena no domínio discursivo da internet pode contribuir também para a discussão de "novas" formas de exclusão e inclusão e, pois, de poder.

Em pleno século XXI, o índigena brasileiro ainda carrega o estereótipo de não trabalhador, sobretudo quando se trata de sua inclusão no mercado de trabalho, apontando para uma nova forma de exclusão: o ciberbullying.

\section{REFERÊNCIAS}

AUTHIER-REVUZ, J. Palavras incertas: as não coincidências do dizer. Trad. Cláudia R. C. Pfeiffer ET. AL. Campinas-SP. Editora da UNICAMP, 1998,

CORACINI, Maria José. A celebração do outro: arquivo, memória e identidade: línguas (materna e estrangeira), plurilinguismo e tradução/ Maria José Coracini. Campinas: Mercado de Letras, 2007.

FOUCAULT, Michel. Method. A arqueologia do saber. Tradução de Luiz Felipe Baeta Neves. 7. ed. Rio de Janeiro: Forense Universitária, [Trabalho original publicado em 1969], 2007.

FERREIRA, Aurélio Buarque de Holanda. Minidicionário da lingua portuguesa. Coordenação de Edição de Marina Baird Ferreira: equipe de lexicografia, Margarida dos Anjos. 7. ed. Curitiba. Ed: Positivo; 2008.

FREITAS, M. E.; HELOANI, Roberto; BARRETO, M. Assédio Moral no Trabalho. São Paulo: Cengage Leaning, 2008.144p.

GUERRA, V.M.L. O indígena de Mato Grosso do Sul: práticas identitárias e culturais. São Carlos: Pedro \& João, 2010. 140p.

ORLANDI, E. P. Análise de discurso: princípios e procedimentos. 8. ed. Campinas: Pontes, 1999. 
Língua e conhecimento linguístico: para uma história das ideias no Brasil. São Paulo: Cortez, 2002.

Unicamp, 2007.

As formas do silêncio: no movimento dos sentidos. 6. ed. Campinas:

PÊCHEUX, M. Análise automática do discurso. In: GADET, F. E HAK, T. Por uma análise automática do discurso. Uma introdução à obra de M. Pêcheux. Campinas: UNICAMP, 1990.

PROENÇA, Gustavo: Povos Indígenas: conheça os direitos previstos na Constituição. Reportagem disponível em EBC - Agência Brasil, http://agenciabrasil.ebc.com.br/direitos-humanos/noticia/2017-04/povos-indigenasconheca-os-direitos-previstos-na-constituicao. Acesso em julho/2017.

RIFFEL, Birgit Yara Frey; RODRIGUES, Jackeline Mendes. Sujeitos inclusos, sujeitos governamentais: discursividades sobre a inclusão no currículo escolar. In: UYENO, Elzira Yoko. CAVALLARI, Juliana Santana; MASCIA, Márcia AP. Amador (Orgs). Mal-estar na inclusão: como (não) se faz. Campinas: Mercado das Letras, 2014; p. 225.

Recebido em: agosto de 2017.

Aprovado em: outubro de 2017.

Como citar este trabalho:

NUNES, F. F. Indigena, cyberbulliyng e a estereotipação do sujeito no mercado de trabalho. Traços de linguagem, v. 1, n. 2, p. 43-49, 2017. 